Short Communication

Human and Medical Genetics

\title{
Growth Hormone insensitivity (Laron syndrome): Report of a new family and review of Brazilian patients
}

Thais R. Villela $^{1}$ (iD , Bruna L. Freire ${ }^{2,3}$, Nathalia T. P. Braga ${ }^{1}$, Rodrigo R. Arantes ${ }^{1}$, Mariana F. A. Funari ${ }^{3}$, Alexander A. L. Jorge ${ }^{2}$ iD and Ivani N. Silva ${ }^{1}$

${ }^{1}$ Universidade Federal de Minas Gerais, Faculdade de Medicina, Hospital das Clínicas, Divisão de Endocrinologia Infantil e do Adolescente, Belo Horizonte, MG, Brazil.

${ }^{2}$ Universidade de São Paulo, Hospital das Clínicas da Faculdade de Medicina, Unidade de Endocrinologia Genética, São Paulo, SP, Brazil.

${ }^{3}$ Universidade de São Paulo, Hospital das Clínicas da Faculdade de Medicina, Unidade de Endocrinologia do Desenvolvimento, Laboratório de Hormônios e Genética Molecular, São Paulo, SP, Brazil.

\begin{abstract}
Laron's syndrome (LS) is a rare genetic disorder characterized by insensitivity to growth hormone (GH). Up to the present time, over 70 mutations of $\mathrm{GH}$ receptor (GHR) gene have been identified leading to $\mathrm{GH} / \mathrm{insulin}$-like growth factor type 1 (IGF1) signaling pathway defect. The number of LS patients worldwide is unknown, as many are probably undiagnosed. We report two sibs from a consanguineous family from Minas Gerais, southeastern Brazil. The parents have three children. The older, a 4-years-old girl was $80.2 \mathrm{~cm}$ tall (-5.7 SDS height/age), and the youngest sister, aged 3 years, was $73.2 \mathrm{~cm}$ tall (-5.82 SDS height/age). Their clinical and biochemical features are typical of LS patients, such as high serum level of GH and low IGF1 concentrations. A homozygous c.1A>T nucleotide substitution in GHR exon 2 in the probands' samples was identified. Their parents and healthy sister are heterozygous for the same variant that abolishes the translation initiation codon of GHR. This mutation has not been reported in Brazilian patients and was previously associated with an LS phenotype in a single 29-year-old Spanish man. In addition to this case report, we summarize the main characteristics and molecular data of the 21 LS Brazilian patients who have been published to date.
\end{abstract}

Keywords: Laron Syndrome, growth hormone, growth hormone receptor, genetics.

Received: July 10, 2018; Accepted: 20 February, 2019.

Laron's syndrome (LS) is a rare genetic disorder characterized by inability to respond to endogenous or exogenous growth hormone $(\mathrm{GH})$. It is associated with mutations in the GH receptor (GHR; OMIM: *600946), leading to GH/insulin-like growth factor type 1 (IGF1) signaling pathway defect. Currently, instead of being recognized as a single entity, it is accepted as a broad diagnostic category, comprising a range of molecular defects in the GH-IGF1 axis. In most cases, LS is determined by a fully penetrant autosomal recessive mechanism seen more commonly in consanguineous families and, in the vast majority, a molecular defect has been identified involving either homozygous or compound heterozygous mutations. The GHR gene is located on the short arm of chromosome 5 and includes 9 coding exons (Fang et al., 2007). Up to the present time,

Send correspondence to Thais Ramos Villela. Universidade Federal de Minas Gerais, Faculdade de Medicina, Hospital das Clínicas, Divisão de Endocrinologia Infantil e do Adolescente, Belo Horizonte, MG, Brasil, Av. Alfredo Balena, 190, 30130-100 - Belo Horizonte, MG, Brazil. E-mail: thaisramosvillela@gmail.com. over 70 mutations of GHR gene have been identified including deletions, missense and nonsense point mutations and at splice site. Different phenotypes may occur with the same mutation and within the same family (David et al., 2011). Homozygous mutations in the signal transducer and activator of transcription 5B gene (STAT5B; OMIM: *604260) were also described in patients with GHI (Pugliese-Pires et al., 2010). STAT5B is a critical molecule involved in GHR signal transduction, mediating growthpromoting actions. In addition to its role in growth-promoting actions, STAT5B is also involved in the immune system regulation (Pugliese-Pires et al., 2010).

Patients with LS have characteristic biochemical features, such as high (or normal) serum level of GH and low IGF1 concentration (Laron, 2004; Laron et al., 2012). Clinically it is characterized by dwarfism, obesity, small genitalia in the boys, and severe hypoglycemia. Patients present a typical head configuration, a small face and a protruding forehead, resulting in a saddle nose. Their voices are highpitched and they are sparse haired. Phenotypically they re- 
sembled what was recognized as GH deficiency (Laron and Kauli, 2016). The majority of patients with STAT5B mutations also present severe immune dysregulation and elevated prolactin levels.

The number of known and/or published LS patients is around 350. Most cases have been reported from the Mediterranean region and Southern Ecuador, and a few cases from South America (Laron, 2016; Laron and Kauli, 2016). In Brazil, 19 patients with LS have been reported so far. Most of them carry the E180 splice mutation (c.594A $>\mathrm{G}$, p.V199_M208 del; rs121909360) (Jorge et al., 2005; Goncalves et al., 2014). In this report, two sibs from a consanguineous family, with a mutation in the exon 2 of $G H R$, are described.

A 4-year-old girl (patient 1) was evaluated for short stature. She has presented severe growth retardation since the first postnatal year. She was $80.2 \mathrm{~cm}$ tall $(-5.7$ SDS height/age), had a BMI of 15.4 (-0.2 SDS) and a 2 year bone age. Parents are first cousins with no relevant medical history. They were born in Minas Gerais, southeastern Brazil, and had three children. She is the oldest sibling. Length at birth was $46 \mathrm{~cm}$ (-1.7 SDS for age) and weight $3.450 \mathrm{~kg}$ (0.5 SDS for age). Clinical examination revealed typical features suggestive of LS: prominent forehead, depressed nasal bridge and high-pitched voice. At her latest visit, she was 9 years old, $105.5 \mathrm{~cm}$ tall (-4.95 SDS height/age), 21.1 $\mathrm{kg}$ (-2.06 SDS weight/age) and had a BMI of 19.0 (1.01 SDS). The patient started the exchange of deciduous teeth at 8.5 years old. Nowadays she has two permanent teeth and the remaining 22 are deciduous. Delay of dentition is also a LS characteristic(Campbell et al., 2009; Laron and Kauli, 2016). The middle sister was 6 years old, $116.3 \mathrm{~cm}$ tall $(0.3$ SDS) and had no complaints. The 3-year-old youngest sister (patient 2) was $73.2 \mathrm{~cm}$ tall (-5.82 SDS height/age), weighed $8.3 \mathrm{~kg}(-5.92 \mathrm{SDS}$ weight/age) and had a BMI of 15.5 (-0.46 SDS). Length at birth was $46 \mathrm{~cm}$ (-1.7 SDS for age) and weight $3400 \mathrm{~g}$ (0.4 SDS for age). She also presented typical LS features, including sparse hair and late closure of the fontanelles.

The workup performed for disclosing short stature etiology (blood count, kinetics of iron, urinalysis, renal and hepatic function, lipid metabolism, cortisol, TSH and free T4, acid-base equilibrium, calcium metabolism, sweat test, and antibodies for Celiac Disease) was normal for both patients, except for the GH axis evaluation (Table 1).
During follow-up, both patients presented hyperlipidemia. Patient 1 had total cholesterol $(\mathrm{TC})=305$ $\mathrm{mg} / \mathrm{dL}$, with LDL-C $=242 \mathrm{mg} / \mathrm{dL}(\mathrm{RV}<100 \mathrm{mg} / \mathrm{dL})$ and patient 2 had TC $=240 \mathrm{mg} / \mathrm{dL}$ and LDL-C $=177 \mathrm{mg} / \mathrm{dL}$. After nutritional interventions, slight improvement in cholesterol levels was observed. In their latest visit, patient 1 had $\mathrm{TC}=243 \mathrm{mg} / \mathrm{dL}$ and $\mathrm{LDL}-\mathrm{C}=157 \mathrm{mg} / \mathrm{dL}$ and patient $2 \mathrm{had}$ $\mathrm{TC}=264 \mathrm{mg} / \mathrm{dL}$ and LDL-C=190 mg/dL. Parents had normal cholesterol levels. The neuropsychomotor development of both patients was normal for their age.

Based on clinical suspicions of severe GH insensitivity, genomic DNA was isolated from peripheral blood leukocytes from the two probands. GHR exons 2-10 (reference sequence NM_000163.4) were amplified using specific intronic primers to cover the entire coding region (primer sequences and amplification protocols will be sent upon request). PCR products were directly sequenced by the dideoxy chain-termination method and analyzed by an autosequencer. A homozygous c.1 A $>$ T nucleotide substitution in GHR exon 2 in the probands samples was identified. Their parents and healthy sister are heterozygous for the same variant. This variant, which abolishes the translation initiation codon of GHR (p.Met1?), is absent in large public data bases (ABraOM: http://abraom.ib.usp.br/ and gnomAD http:/gnomad.broadinstitute.org/). It has been previously associated with an LS phenotype in a Spanish patient (Quinteiro et al., 2002) and classified as pathogenic according to ACMG-AMP criteria (Richards et al., 2015).

Growth hormone insensitivity syndrome (GHI) was first described in 1966 by Laron and collaborators (Laron et al., 1966). They reported a Jewish child born in Yemen presenting severe growth deficit. The child had clinical characteristics compatible to $\mathrm{GH}$ deficiency, although showing high plasma levels of this hormone. This patient was from a consanguineous family and had two siblings presenting the same pattern. Five older siblings had normal height. After publication of these data, the same group collected another 22 patients from 14 consanguineous families, all coming from the Middle East or Arabian Peninsula and with the same characteristics. Until then, the etiology of short stature was attributed to an inactive GH molecule (Laron et al., 1968).

In 1989, cloning of the GH receptor enabled the identification of partial gene deletion in the GH receptor in two patients (Laron and Kauli, 2016). The first was a

Table 1 - GH axis evaluation of two Brazilian siblings with LS.

\begin{tabular}{lcccc}
\hline Patient & Age at the test & $\begin{array}{c}\text { IGF } 1 \\
(\mu \mathrm{g} / \mathrm{L})\end{array}$ & $\begin{array}{c}\text { IGFBP3 } \\
(\mathrm{mg} / \mathrm{L})\end{array}$ & $\begin{array}{c}\text { Basal GH } \\
(\mathrm{ng} / \mathrm{mL})\end{array}$ \\
\hline 1 & 4 years old & 12.3 & 0.70 & 21.5 \\
& & $(\mathrm{RV}: 49-289)$ & $(\mathrm{RV}: 1.0-4.7)$ & 0.5 \\
2 & 1 year old & 79 & $(\mathrm{RV}: 0.7-3.9)$ & 11.4 \\
\hline
\end{tabular}


35-year-old male born from related parents of Jewish Iraqi origin. He reached a final height of $128.3 \mathrm{~cm} \mathrm{(-7.3} \mathrm{SDS} \mathrm{for}$ age). The second was a girl sharing the same origin. At 8 years and 10 months her height was $104 \mathrm{~cm}$ (-4.2 SDS for age). No serum GH binding protein activity was found in both of them (Godowski et al., 1989).

The total number of patients with GHI worldwide is not known, as many are probably undiagnosed (Laron and Kauli, 2016). It is a rare disorder and 21 Brazilian patients have been reported to date, including the present. Among the reported LS Brazilian patients, 18 have undergone molecular studies. The first two male sibs with GHI reported from Brazil were homozygous for a substitution of $\mathrm{T}$ for $\mathrm{G}$ at the -1 position of the 3 'splice consensus sequence of intron 6 (c.619-1 G>C). Parents were first cousins from Italy (Saldanha and Toledo, 1981; Berg et al., 1993). A third patient carried a homozygous mutation, replacing serine by isoleucine in the codon 244 of exon 7 (p.S244I). Parents are also consanguineous (Jorge et al., 2004). Another patient carried a mutation in homozygous state, adenine duplication at nucleotide 338 (c.338dupA) of the exon 5. This nucleotide alteration causes a premature termination signal at codon 113 (p.Try $113^{*}$ ), predicting a truncated GHR. It determines a failure in receptor function caused by the lack of amino acids comprising the transmembrane and intracellular regions of GHR proteins (Diniz et al., 2008). Another 8 patients, from six families, carried a homozygous substitution of guanine by adenine in codon 198 of exon 6 (c.594 $\mathrm{A}>\mathrm{G}$ ), creating an abnormal splice site deleting 8 amino acids from the extracellular domain of GHR (Jorge et al., 2005; Goncalves et al., 2014). This mutation in codon 198 is also known as E180 splice mutation. Four patients with STATB5 mutations, from two different families, have been reported in the South of Brazil. The first two carried a heterozygous missense mutation at exon 5 and both siblings carried a deletion of four nucleotides in exon 5 of STAT5B (Pugliese-Pires et al., 2010). Two siblings from another family, who died of respiratory failure, had their mutations inferred because their parents were heterozygous carriers for STAT5B c.424_427del mutation. The prevalence of their STAT5B mutation in the South of Brazil was higher than the frequency observed in public databases, supporting the existence of a founder effect (Scalco et al., 2017). Another three patients with dwarfism, high serum levels of GH and low IGF1 concentrations were reported in Brazil, but they hadnt undergone molecular tests (Jorge, 2008).

Finally, in the present paper, we describe two sibs with LS, carrying a homozygous A-T transversion in exon 2. This transversion occurs at the first base pair of the translation initiation codon of the gene. As a result, the methionine marking the starting of the reading frame is replaced by a leucine. Both parents are heterozygous for the same mutation. A summary on the data for the Brazilian patients is shown in Table 2.

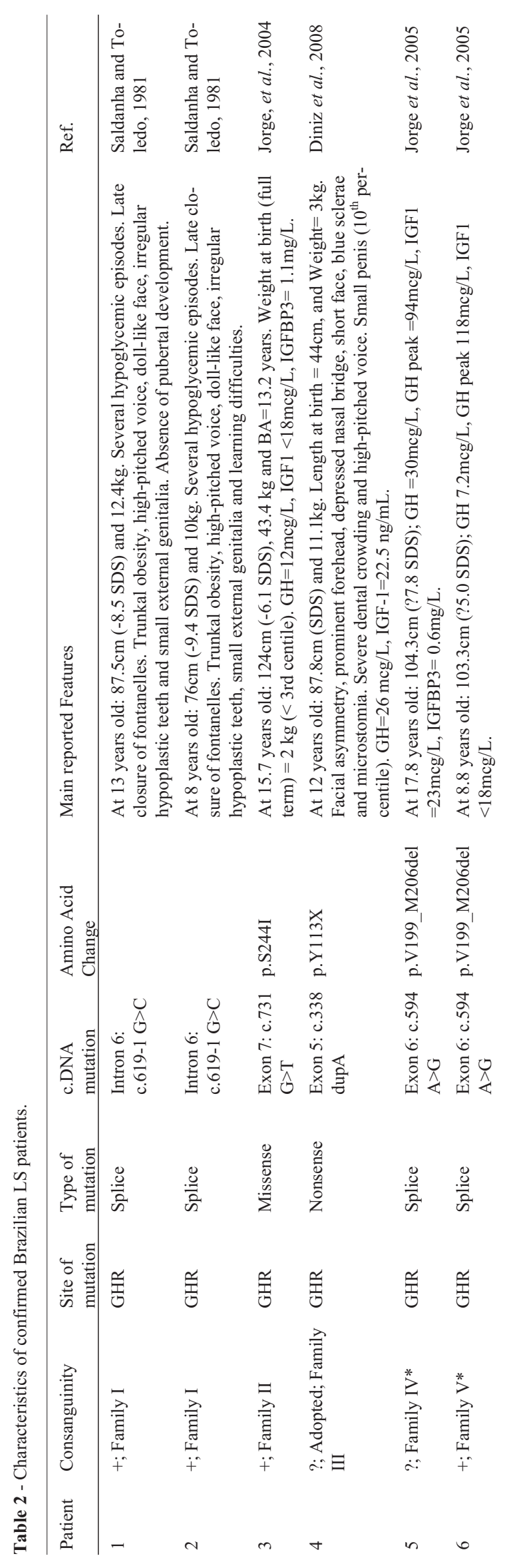




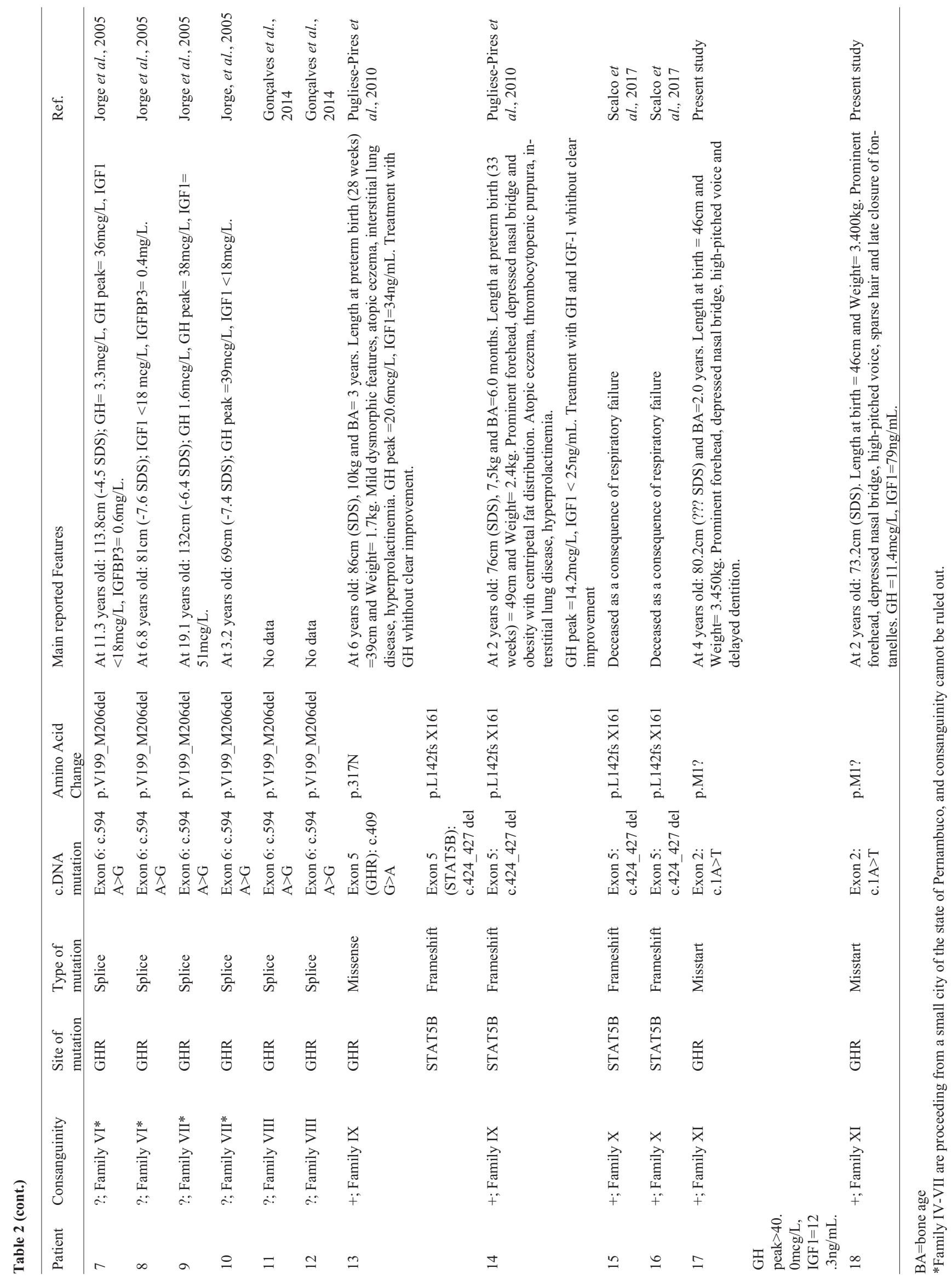


The mutation found in this new Brazilian family was also reported in a single 29-year-old LS Spanish patient, whose parents of Spanish origin were consanguineous. At the age of 10 he was unsuccessfully treated with GH. He reached a final height of $124.4 \mathrm{~cm}$ (-7.5 SDS for height) (Quinteiro et al., 2002).

Research in the field of GHI due to mutations affecting GH action has evolved considerably since the original description of the severe phenotype related to homozygous GHR mutation over 50 years ago. To date over 70 mutations have been reported (David et al., 2011). The most frequent GHR mutation, E180 splice, seems to have originated from a single ancestor and spread to Latin America (Goncalves et al., 2014). The mutation reported here, in this new family, has never been reported in Brazilian patients and could have followed the same pathway. Up to now, no information has shed light on these specific aspects.

In conclusion, we reported a new Brazilian family showing a rare GHR mutation only found previously in a single LS Spanish patient. These findings, according to what has been described above, could be an additional evidence for the possible origin from a single common ancestor of these individuals.

\section{Acknowledgments}

This work was financially supported by Grants 2013/03236-5 (to A.A.L.J.) from the São Paulo Research Foundation (FAPESP) and Grant 304678/2012-0 (to A.A.L.J.) from the National Council for Scientific and Technological Development (CNPq).

\section{Conflict of Interest}

The authors declare that there is no conflict of interest that could be perceived as prejudicial to the impartiality of the reported research.

\section{Author contributions}

TRV and INS conceived and designed the study, BLF, MFAF and AALJ conducted the experiments, TRV, RRA and INS analyzed the data and TRV, NTPB, AALJ and INS wrote the manuscript. All the authors read and approved the final version.

\section{References}

Berg MA, Argente J, Chernausek S, Gracia R, Guevara-Aguirre J, Hopp M, Perez-Jurado L, Rosenbloom A, Toledo SP and Francke U (1993) Diverse growth hormone receptor gene mutations in Laron syndrome. Am J Hum Genet 52:9981005.

Campbell R, Weinshel R, Backeljauw P, Wilson S, Bean J and Shao M (2009) Dental development in children with growth hormone insensitivity syndrome: Demirjian analysis of serial panoramic radiographs. Cleft Palate Craniofacial J 46:409-414.
David A, Hwa V, Metherell LA, Netchine I, Camacho-Hubner C, Clark AJ, Rosenfeld RG and Savage MO (2011) Evidence for a continuum of genetic, phenotypic, and biochemical abnormalities in children with growth hormone insensitivity. Endocr Rev 32:472-97.

Diniz ET, Jorge AA, Arnhold IJ, Rosenbloom AL and Bandeira F (2008) Novel nonsense mutation (p.Y113X) in the human growth hormone receptor gene in a Brazilian patient with Laron syndrome. Arq Bras Endocrinol Metabol 52:12641271.

Fang P, Riedl S, Amselem S, Pratt KL, Little BM, Haeusler G, Hwa V, Frisch H and Rosenfeld RG (2007) Primary growth hormone $(\mathrm{GH})$ insensitivity and insulin-like growth factor deficiency caused by novel compound heterozygous mutations of the GH receptor gene: genetic and functional studies of simple and compound heterozygous states. J Clin Endocrinol Metabol 92:2223-2231.

Godowski PJ, Leung DW, Meacham LR, Galgani JP, Hellmiss R, Keret R, Rotwein PS, Parks JS, Laron Z and Wood WI (1989) Characterization of the human growth hormone receptor gene and demonstration of a partial gene deletion in two patients with Laron-type dwarfism. Proc Natl Acad Sci U S A 86:8083-8087.

Goncalves FT, Fridman C, Pinto EM, Guevara-Aguirre J, Shevah O, Rosembloom AL, Hwa V, Cassorla F, Rosenfeld RG, Lins TS et al. (2014) The E180splice mutation in the GHR gene causing Laron syndrome: Witness of a Sephardic Jewish exodus from the Iberian Peninsula to the New World? Am J Medic Genet Part A 164a:1204-1208.

Jorge AA (2008) Short stature investigation: Clinical, laboratorial and genetic aspects concerning the growth hormone insensitivity (GHI). Arq Bras Endocrinol Metabol 52:1056-65.

Jorge AA, Souza SC, Arnhold IJ and Mendonca BB (2004) The first homozygous mutation (S226I) in the highly-conserved WSXWS-like motif of the GH receptor causing Laron syndrome: Supression of GH secretion by GnRH analogue therapy not restored by dihydrotestosterone administration. Clin Endocrinol 60:36-40.

Jorge AA, Menezes Filho HC, Lins TS, Guedes DR, Damiani D, Setian N, Arnhold IJ and Mendonca BB (2005) Founder effect of E180splice mutation in growth hormone receptor gene (GHR) identified in Brazilian patients with GH insensitivity. Arq Bras Endocrinol Metabol 49:384-389.

Laron Z (2004) Laron syndrome (primary growth hormone resistance or insensitivity): The personal experience 1958-2003. J Clin Endocrinol Metabol 89:1031-1044.

Laron Z (2016) Epilogue: The future of Laron syndrome - the need for changes. Growth Horm IGF Res 28:79-80.

Laron Z and Kauli R (2016) Fifty seven years of follow-up of the Israeli cohort of Laron Syndrome patients-From discovery to treatment. Growth Horm IGF Res 28:53-6.

Laron Z, Pertzelan A and Mannheimer S (1966) Genetic pituitary dwarfism with high serum concentation of growth hormone- a new inborn error of metabolism? Isr J of Med Sci 2:152-155.

Laron Z, Pertzelan A and Karp M (1968) Pituitary dwarfism with high serum levels of growth hormone. Isr $\mathrm{J}$ of Med Sci 4:883-894.

Laron Z, Iluz M and Kauli R (2012) Head circumference in untreated and IGF-I treated patients with Laron syndrome: Comparison with untreated and hGH-treated children with 
isolated growth hormone deficiency. Growth Horm IGF Res 22:49-52.

Pugliese-Pires PN, Tonelli CA, Dora JM, Silva PC, Czepielewski M, Simoni G, Arnhold IJ and Jorge AA (2010) A novel STAT5B mutation causing GH insensitivity syndrome associated with hyperprolactinemia and immune dysfunction in two male siblings. Eur J Endocrinol 163:349-355.

Quinteiro C, Castro-Feijoo L, Loidi L, Barreiro J, de la Fuente M, Dominguez F and Pombo M (2002) Novel mutation involving the translation initiation codon of the growth hormone receptor gene (GHR) in a patient with Laron syndrome. J Pediatr Endocrinol Metabol 15:1041-1045.

Richards S, Aziz N, Bale S, Bick D, Das S, Gastier-Foster J, Grody WW, Hegde M, Lyon E, Spector E et al. (2015) Standards and guidelines for the interpretation of sequence variants: A joint consensus recommendation of the American
College of Medical Genetics and Genomics and the Association for Molecular Pathology. Genet Med 17:405-424.

Saldanha PH and Toledo SP (1981) Familial dwarfism with high IR-GH: Report of two affected sibs with genetic and epidemiologic considerations. Hum Genet 59:367-372.

Scalco RC, Goncalves FT, Santos HC, Cardena M, Tonelli CA, Funari MFA, Aracava RM, Pereira AC, Fridman C and Jorge AAL (2017) Growth hormone insensitivity with immune dysfunction caused by a STAT5B mutation in the south of Brazil: Evidence for a founder effect. Genet Mol Biol 40:436-441.

Associate Editor: Angela Vianna-Morgante

License information: This is an open-access article distributed under the terms of the Creative Commons Attribution License (type CC-BY), which permits unrestricted use, distribution and reproduction in any medium, provided the original article is properly cited. 